\title{
X-ray spectral microanalysis of hardened additive products made of electroerosion cobalt-chromium alloys
}

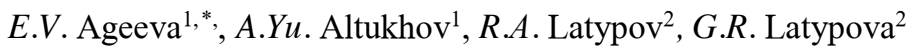 \\ ${ }^{1}$ Southwest State University, 305040 Kursk, Russian Federation \\ ${ }^{2}$ Moscow Polytechnic University, 107023 Moscow, Russian Federation
}

\begin{abstract}
This article presents the results of an X-ray spectral microanalysis of cobalt-chromium alloys based on particles of the of the tungsten nickel iron alloy dispersed by electric erosion, obtained in alcohol. It has been experimentally proved that a part of oxygen is present in the cobalt-chromium alloy of particles of the cobalt-chromiummolybdenum alloy dispersed by electric erosion. All other elements are distributed relatively evenly over the volume of particles. It is shown that $\mathrm{Co}, \mathrm{Cr}$ and $\mathrm{Mo}$ are the main elements of the (CoCrMo) alloy dispersed by electric erosion.
\end{abstract}

\section{Introduction}

Additive technologies are among the most advanced and demanded in the world. In this regard, the creation of the possibility of their wider use is a very important and urgent task. Accurate production of the shape is the most important, but not the only task that is solved in the production of parts. No less principal are such properties as: elasticity and plasticity, strength and wear resistance, etc. [1-5].

It is known that high-temperature action on the workpiece material, which accompanies any of the known additive processing processes, negatively affects the above properties. The most important task of additive technologies is to provide a high-quality material structure and high performance properties of the resulting part with a multiple increase in productivity [6-10].

The aim of the research is to develop a technology in which the surface hardening process is added to the additive processing processes. In addition, it is proposed to consider the issues of creating a gradient heterogeneous structure, due to the use of metal-powder compositions, similar in composition, but different in properties, based on Co-Cr alloys.

The suggested methods make it possible to structure, compact, and strengthen the material of the grown layer. Thus, we achieve the modification of the material and the surface layer of products at different levels. By applying the proposed approach, it is planned to achieve a qualitative increase in the physical, mechanical and operational properties of additive parts.

\footnotetext{
* Corresponding author: ageeva-ev@yandex.ru
} 
For the practical implementation of additive technologies in terms of the need to use spherical powders, an electrodispersion technology is proposed, which is distinguished by relatively low energy costs and environmental friendliness.

One of the advantages of the technology is the use of waste as starting materials, which is much cheaper than pure components used in traditional technologies. In addition, this technology allows to control the size and shape distribution of the resulting powders due to the possibility of regulating the energy parameters of the process in a wide range $[11,12]$.

The purpose of this research was to study the sintering ability of electroerosive cobaltchromium powders manufactured for additive products. It was also important to carry out an X-ray spectral microanalysis of cobalt-chromium alloys based on particles of the tungsten nickel iron alloy dispersed by electroerosion, obtained in alcohol.

\section{Materials and Methods}

Cobalt chromium powders were obtained by electrodispersion of the (CoCrMo) alloy waste in alcohol. The average particle size of the obtained particles was $52.5 \mu \mathrm{m}$, the arithmetic value was $52.496 \mu \mathrm{m}$. For dispersion of W-Ni-Fe alloy wastes, an installation protected by RF Patent No. 2449859 was used. Additive samples were obtained by laser sintering on additive machines from metal-powder compositions based on $\mathrm{Co}-\mathrm{Cr}$ alloys. In order to impart the required physical, mechanical and operational properties to the additive samples, volumetric and surface hardening by static-pulse treatment was performed.

$\mathrm{X}$-ray spectral analysis of the obtained samples was performed using an EDAX energydispersive X-ray analyzer (Figure 1) built into a QUANTA 600 FEG scanning electron microscope.

With the help of scanning electron microscopy, it was possible to carry out direct analysis of powder particles with a sufficiently high resolution. With a scanning electron microscope we could observe a three-dimensional image of the structure under study at a large depth of focus (Figure 1).

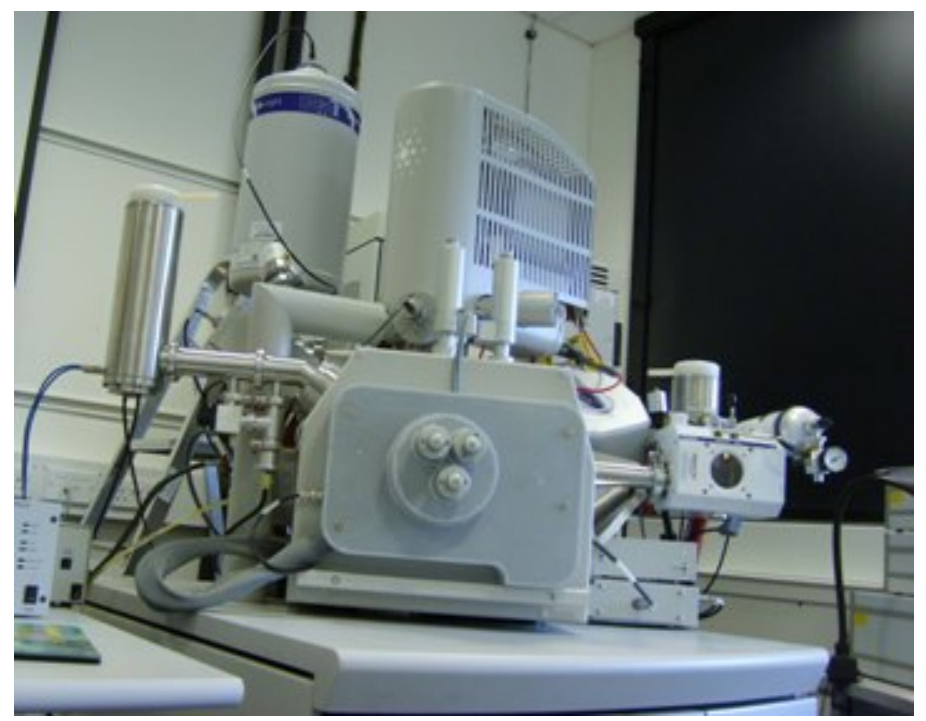

Fig. 1. A scanning electron microscope «QUANTA 600 FEG»

The fractional composition of the W-Ni-Fe powders was studied using an Analysette 22

NanoTec laser analyzer (Figure 2). 


\section{Results}

The generalized results of the research of the microstructure and X-ray spectral microanalysis of heavy tungsten pseudo alloys from the particles of the W-Ni-Fe 95 alloy dispersed by electric erosion in distilled water are shown in Figure 2. Points 1 and 2 in the figure correspond to the spectra of characteristic X-ray radiation. In the spectra, each chemical element corresponds to a peak of a certain height.

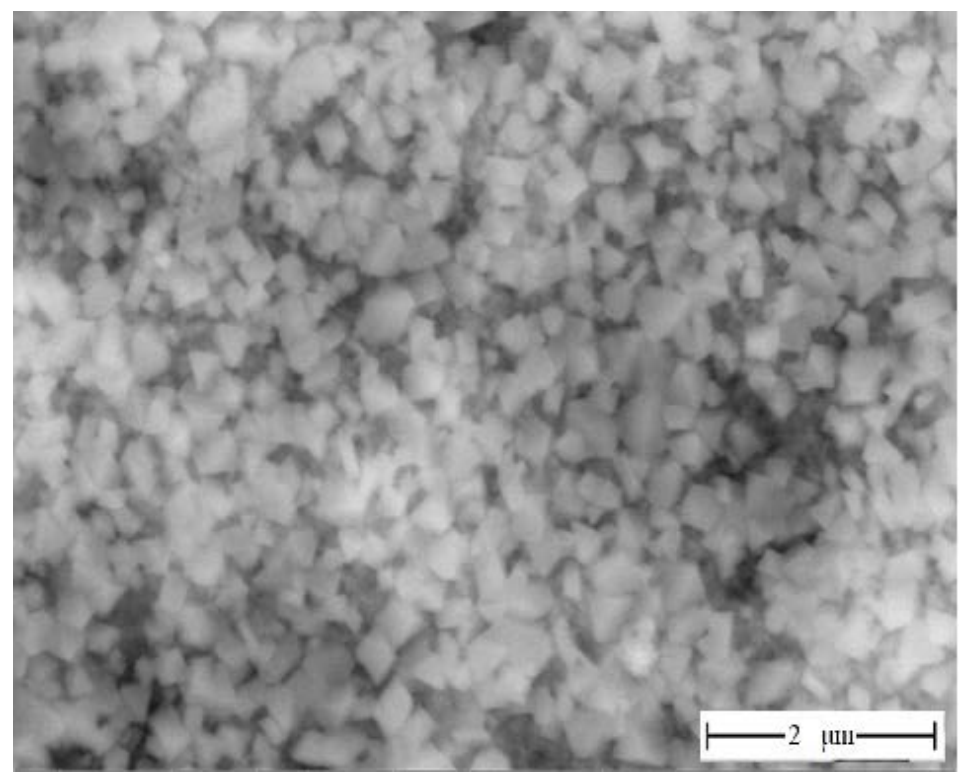

a)

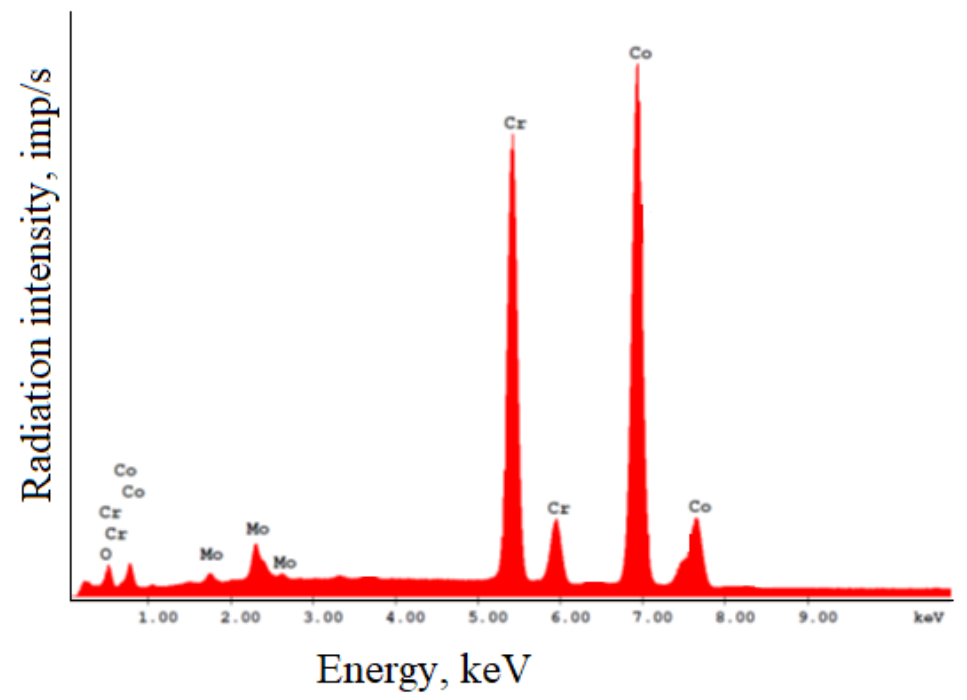

b)

Fig. 2. Cobalt-chromium alloy of particles dispersed by electric erosion: a) microstructure; b) elemental composition 
It has been experimentally proved that a part of oxygen is present in the cobaltchromium alloy of particles of the cobalt-chromium-molybdenum (CoCrMo) alloy dispersed by electric erosion. All other elements are distributed relatively evenly over the volume of particles. It is shown that $\mathrm{Co}, \mathrm{Cr}$ and $\mathrm{Mo}$ are the main elements of the CoCrMo alloy dispersed by electric erosion.

\section{Conclusion}

The results of the conducted fundamental research will contribute to the development of the theoretical foundations of the formation of mechanical engineering products obtained from metal-powder compositions based on Co-Cr alloys, as well as the application of the obtained regularities for practical use in the form of developed technological processes for critical mechanical engineering products.

The scientific significance of solving the fundamental problem of the development of theoretical provisions, methodology and tools, allowing to ensure the production of mechanical engineering products obtained by additive technologies from metal-powder compositions based on $\mathrm{Co}-\mathrm{Cr}$ alloys, which contribute to an increase in the operational reliability, durability and safety of machines, in relation to the specifics of critical parts of mechanical engineering, associated with new scientific results that allow solving fundamentally new problems in the industrial application of macro- and nanopowders.

The practical significance of the research lies in increasing the operational reliability, durability and safety of critical parts of mechanical engineering. At the same time, increasing the operational reliability, durability and safety of machines has a positive effect on the consumption of natural resources and, accordingly, on the environmental safety of our country. Also, the use of new technologies can significantly reduce the cost of maintenance and repair of machines.

The work was supported by the Russian Science Foundation. Project number is 17-79-20336-P.

\section{References}

1. Wang Z, Guana K, Gaoa M. 2012 Journal of Alloys and Compounds513 518-523.

2. Biamino S, Penna A, AckelidU 2011 Intermetallics. 19 776-781.

3. Gu D D, Meiners W, Wissenbach K, Poprawe R. 2012 International Materials Reviews57 133-164.

4. Song B, Dong S, Zhang B 2012 Materials \& Design35 120-125.

5. Song B, Dong S, Coddet P 2012 Surface and Coatings Technology206 4704-4709.

6. Karlsson J, Snis A, Engqvist H, Lausmaa J 2013 Journal of Materials Processing Technology213 2109-2118.

7. Safdar A, He H Z, Wei L Y, Snis A 2012 Rapid Prototyping Journal18 401-408.

8. Loeber L, Biamino S, Ackelid U 2011 Solid freeform fabrication proceedings 11 547556.

9. Gu D D, Meiners W, Wissenbach K, Poprawe R. 2012 International Materials Reviews57 133-164.

10. Wang Z, Guana K, Gaoa M 2012 Journal of Alloys and Compounds513 518-523.

11. Ageev E V, Latypov R A 2014 Russian Journal of Non-Ferrous Metals 6 577-580.

12. Latypov R A, Latypova G R, Ageev E V, Altukhov A Y, Ageeva E V 2017 Russian metallurgy (Metally). 12 1083-1085. 